\title{
Characterisation of two-phase flow and its impact on the performance of a Polymer Electrolyte Membrane fuel cell stack
}

\author{
G. Karimi*, F. Jafarpour \\ and M. Binazadeh
}

Department of Chemical and Petroleum Engineering, Shiraz University, Shiraz, Fars, Iran

E-mail: ghkarimi@shirazu.ac.ir E-mail: fjafarp@ncsu.edu. E-mail: mojtaba@nus.edu.sg

*Corresponding author

\section{Li}

Department of Mechanical and Mechatronics Engineering at the University of Waterloo, Ontario, Canada, N2L 3G1, Canada. E-mail: x6li@mecheng1.uwaterloo.ca

\begin{abstract}
Water management is one of the most critical issues for highperformance Polymer Electrolyte Membrane (PEM) fuel cells. A flow network model was developed to study the possibility of two-phase flow inception along the gas flow channels in the cathode side of a PEM fuel cell stack. The conventional Darcy-Weisbach equation and homogeneous flow model are used to estimate the pressure distributions in the network. The corresponding species concentrations as well as the thermodynamic quality distributions are also calculated. The simulation results have revealed that under certain operating conditions, the quality is lower than one for parts of the stack. However, the amount of the liquified water in the stack is not significant to cause a major pressure drop or an appreciable change in the $\mathrm{O}_{2}$ concentration. Effects of current density and channel diameter on the system quality are also investigated.
\end{abstract}

Keywords: flow network analysis; mathematical modelling; Polymer Electrolyte Membrane; PEM fuel cell; stack; two-phase flow.

Reference to this paper should be made as follows: Karimi, G., Jafarpour, F., Binazadeh, M. and Li, X. (2008) 'Characterisation of two-phase flow and its impact on the performance of a Polymer Electrolyte Membrane fuel cell stack', Int. J. Alternative Propulsion, Vol. 2, No. 1, pp.26-38.

Biographical notes: G. Reza Karimi received his PhD from the University of Toronto, Canada in 1998. He worked as a Research Associate at the University of Toronto and University of Waterloo from 1998 to 2005. He joined Shiraz 
University, Shiraz, Iran in 2005, where he is currently an Assistant Professor of Chemical and Petroleum Engineering. His main research interest and activities are in the area of thermo-fluid science including fuel cell systems.

Farshid Jafarpour is currently a senior student in the Department of Chemical Engineering at the North Carolina State University, Raleigh, North Carolina, USA.

Mojtaba Binazadeh received his BSc in Chemical Engineering from the Shiraz University, Shiraz, Iran, in 2007. He is currently a graduate student in the Department of Chemical and Biomolecular Engineering of the National University of Singapore. His research topic is biodegradation of long chain hydrocarbons.

Xianguo Li received his $\mathrm{PhD}$ from the Northwestern University, Evanston, Illinois, USA in 1989. He joined the University of Victoria, Victoria, BC, Canada as an Assistant Professor in 1992 and University of Waterloo, Waterloo, Ontario, Canada, as an Associate Professor in 1997 and was promoted to the rank of full professor in 2000. His main research interest and activities are in the area of thermal fluid/science, including energy systems and energy storage, various energy conversion devices, propulsion and power generation systems, and transportation fuel cell systems. He is a member of various international and Canadian professional organisations

\author{
Nomenclature \\ A Cross sectional area $\left(\mathrm{m}^{2}\right)$ \\ $C \quad$ Molar concentration $\left(\mathrm{mol} \mathrm{m}^{-3}\right)$ \\ $C_{\mathrm{f}} \quad$ Wall friction coefficient \\ $d_{\mathrm{h}} \quad$ Flow channel hydraulic diameter $(\mathrm{m})$ \\ $D_{\mathrm{h}} \quad$ Manifold hydraulic diameter (m) \\ $F \quad$ Faraday constant $\left(96485^{\circ} \mathrm{C} \mathrm{mole}^{-1}\right)$ \\ $H \quad$ Bipolar plate effective height (m) \\ $J \quad$ Cell current density $\left(\mathrm{A} \mathrm{m}^{-2}\right)$ \\ $l \quad$ Flow channel length (m) \\ $N \quad$ Number of cells/loops/segments/flow channels/turns \\ $\dot{N} \quad$ Molar flow rate $\left(\mathrm{mol} \mathrm{sec}^{-1}\right)$ \\ $P \quad$ Pressure $(\mathrm{Pa})$ \\ Re Reynolds number \\ $\mathscr{S} \quad$ Stoichiometry \\ $T \quad$ Stack temperature (K) \\ $V \quad$ Average velocity $\left(\mathrm{m} \mathrm{sec}^{-1}\right)$ \\ $W \quad$ Bipolar plate effective width (m) \\ $X \quad$ Thermodynamic quality
}




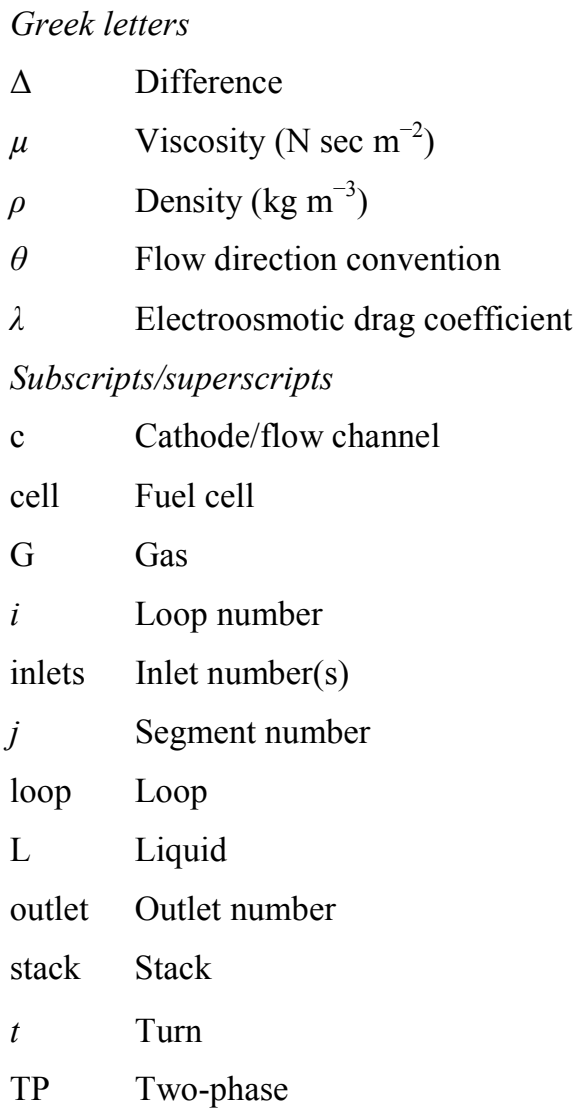

\section{Introduction}

Polymer Electrolyte Membrane (PEM) fuel cells convert the chemical energy of hydrogen and oxygen directly and efficiently into electrical energy and are widely regarded as alter-native stationary and mobile power source. The main characteristics of PEM fuel cells are: they produce water as a byproduct; they have higher efficiency when compared with heat engines; they operate at low temperatures (up to $90^{\circ} \mathrm{C}$ ), which allows a fast start-up; and, they use a solid polymer as the electrolyte, which reduces concerns related to construction, transportation and safety.

During operation of a PEM fuel cell, hydrogen and oxygen are consumed as the fuel and air travel from inlet to outlet; leading to distributions in reaction rates. This distribution of the reaction causes gradients in temperature and water production over the area of the cell. These secondary effects can feedback to change the reaction rate and can lead to local flooding when the local partial pressure of water exceeds the saturation pressure for water at the local temperature. Other effects include water transport across the membrane between the anode and cathode due to electroosmotic drag as well as back diffusion. Hence, the proper design and manufacturing of the fuel and oxidant flow fields is crucial for optimum operation of the PEM fuel cell stacks and could alleviate water management issues in the system. 
Figure 1 Schematic of a Polymer Electrolyte Membrane fuel cell stack (see online version for colours)

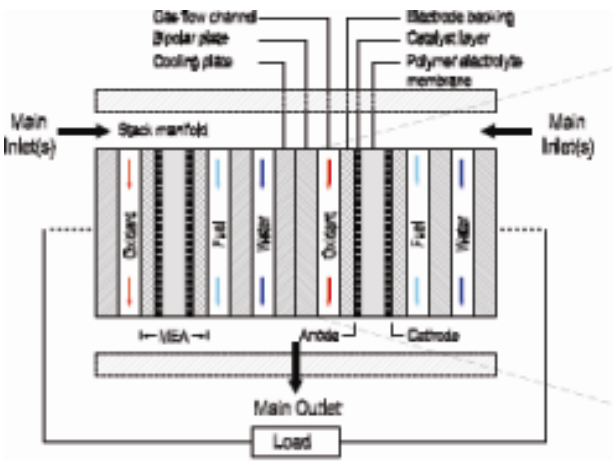

(a)

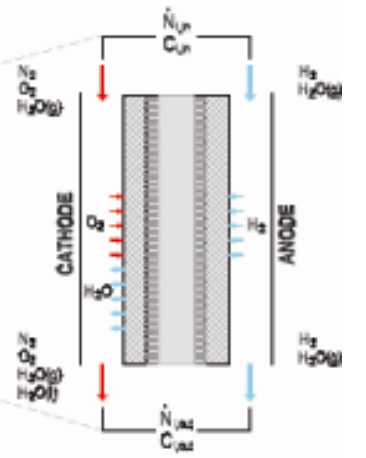

(b)

Many researchers have studied the problem of water management in PEM fuel cells for both steady-state and transient operation (Wang, 2004). However, the effect of flow-field design on PEM fuel cell performance has received less attention. Fell et al. (2002) used a single-phase isothermal Computational Fluid Dynamic model of PEM fuel cell segments to test performance of experimental flow-field designs under differ humidity conditions. Greenway, Shimpalee and Van Zee (2002) used a two-phase, non-isothermal model to study $10 \mathrm{~cm}^{2}$ serpentine laboratory scale flow-field patterns with different flow path lengths and inlet/outlet configurations to study cell performance and distribution uniformity. Experimentally, Li, Chen and Chyu (2005) compared a serpentine pattern to a matrix of individual graphite squares. Commercial-size cells, $200-800 \mathrm{~cm}^{2}$, have more pronounced effects from pressure drop, flooding distribution and non-uniformity in temperature and current distributions due to manifolding constraints. These effects cause stability, durability and performance problems for PEM fuel cell stacks. Shimpalee et al. (2004) explained effects seen in a patented $480 \mathrm{~cm}^{2}$ cell under different cathode humidity conditions, but did not investigate different flow-field patterns. Karimi, Baschuk and Li (2005) studied the effects of inlet-outlet topology and flow field geometry on the performance of a 51-cell PEM fuel cell stack and concluded that symmetric inlet-outlet topologies would provide higher stack performance.

The main objective of this article was to develop a flow network model to estimate the operating conditions under which two-phase flow could be initiated in a PEM fuel cell stack and its influence on the stack performance. The flow network model was applied to the cathode side of a stack, which is more sensitive to the inception of twophase flow. The model presented here is a modified version of a recent model (Karimi, Baschuk and Li, 2005) which can predict the stack performance in terms of pressure, species concentrations and thermodynamic quality distributions in the flow fields.

\section{Model formulation}

Schematic diagram of a typical PEM fuel cell stack is shown in Figure 1. The individual cell, referred to as Membrane Electrode Assemblies (MEAs), is composed of a membrane electrolyte sandwiched in the middle of the cell, and typically contains catalyst and microporous diffusion layers along with gaskets as a single integrated unit. One side of the membrane is referred to as the anode, the other as the cathode. The catalyst layer at 
the anode separates hydrogen molecules into protons and electrons. The membrane permits ion transfer (protons), requiring the electrons to flow through an external circuit before recombining with protons and oxygen at the cathode to form water. This migration of electrons produces useful work.

In practice, oxygen (pure or in air) enters the stack through the main inlet(s), travels along the inlet manifold and is distributed into the flow channels or fields. From the flow fields, $\mathrm{O}_{2}$ diffuses through porous media towards the cathode-membrane interface where it is reduced to form water and heat which are then removed from the system. The rate of oxygen consumed and water produced in the cathode side of a unit cell can be calculated using Faraday's law:

$$
\dot{N}_{\mathrm{O}_{2}}^{\text {cell }}=\frac{J A_{\text {cell }}}{4 F} ; \quad \dot{N}_{\mathrm{H}_{2} \mathrm{O}}^{\text {cell }}=2 \dot{N}_{\mathrm{O}_{2}}^{\text {cell }} .
$$

Water can also be added to the cathode side due to the electroosmotic drag and be transferred from the cathode due to back diffusion. The simultaneous water and oxygen transfer in conjunction with significant pressure variations in the cathodic bipolar plate flow channels can lead to the situations where liquid-vapour two-phase flow could occur. The prediction of this phenomenon is the focus of the current work as described in sections.

\subsection{Stack flow model}

The cross section of a PEM fuel cell stack was shown before in Figure 1. Figure 2 illustrates in more detail the structure of a typical cathodic bipolar plate with inlet and outlet manifolds and three flow channels arranged in a serpentine configuration. To model the two-phase flow distribution in the stack, the complex oxidant flow paths consisting of the main inlet(s), inlet and outlet manifolds and the gas flow channels can be reduced into a graphical flow network as depicted in Figure 3, where each MEA is surrounded by the manifolds and the flow channels. The top manifold supplies the oxidant stream to the flow channels and the unreacted oxygen accompanied with water and nitrogen exit into the bottom manifold, collected and leaves the stack.

Figure 2 Illustration of a bipolar plate with serpentine flow field and three channels per plate

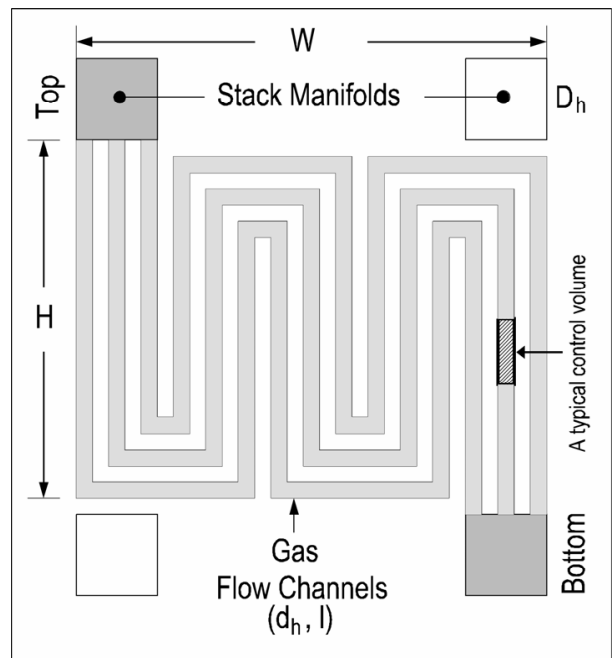


Figure 3 Graphical representation of the stack flow network model (see online version for colours)

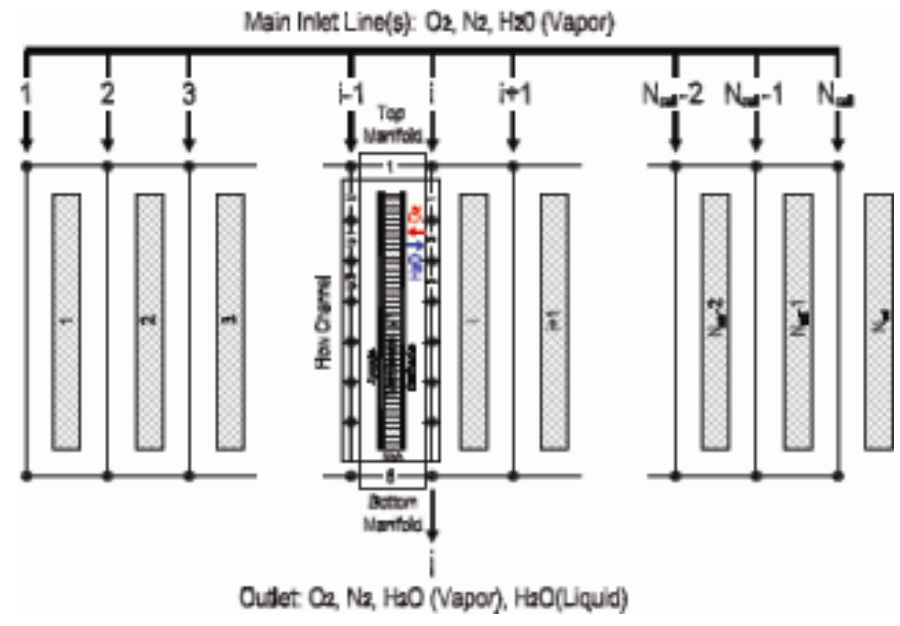

The oxygen reduction starts at the beginning of flow channels right after the oxygen, protons and electrons are brought into contact in the catalytic layer. The reaction rates vary along the flow channels as the species composition and pressure change. In a recent study, Karimi, Baschuk and Li (2005) employed a simplified control volume approach (totally six control volume per cell) to predict the average species concentrations throughout the fuel cell stack for a wide variety of inlet-outlet topologies. In the current work, the flow paths are divided into smaller control volumes, particularly in the flow channels where the majority of transport phenomena occur, to capture in a more detail, the variations in the species concentrations, local pressures and the possibility of twophase flow inception. Within each control volume, it is assumed that the pressure and compositions are uniform. Mass transfers due to electrochemical reactions are considered to take place uniformly along the flow channels resulting in uniform current distribution. The new network model consists of an arbitrary number of loops (associated with each cell), with each loop comprising of $M$ segments: two in the inlet and outlet manifolds, and $(M-2) / 2$ in each flow channel. The interfaces at which any two segments meet are represented by nodes $(\bullet)$ as illustrated in Figure 3 .

The total molar flow rate of $\mathrm{O}_{2}$ entering the cathode side of the stack can be determined by:

$$
\dot{N}_{\mathrm{O}_{2}}^{\text {stack }}=\frac{\mathscr{S}_{\mathrm{c}} N_{\text {cell }} J A_{\text {cell }}}{4 F}
$$

where $\mathscr{S}_{\mathrm{c}}$ is the cathode stoichiometry, $N_{\text {cell }}$ is the total number of fuel cells in the stack, $J$ is the current density and $A_{\text {cell }}$ is the active area of a unit cell, respectively. Total inlet molar flow rate can be calculated by adding the nitrogen and water vapour to the oxygen molar flow rate. The maximum amount of water vapour coming into the cathode corresponds to $100 \%$ relative humidity. 
The distribution of incoming components is governed by the conservation laws. During the electrochemical reaction, $\mathrm{O}_{2}$ is consumed and water is produced. In addition, water can be exchanged between the anode and cathode sides of the stack due to the electroosmotic drag and back diffusion (Karimi, Baschuk and $\mathrm{Li}, 2005$ ). These are all considered to determine the species molar flow rates at different nodes in the flow network. In order to satisfy the conservation of energy, the sum of pressure changes around each of the loops, $i$, should be zero,

$$
\sum_{j=1}^{M} \theta_{i, j} \Delta P_{i, j}=0 \quad\left(i=1,2,3, \ldots, N_{\text {loop }}\right)
$$

where $\theta_{i, j}$ is a sign convention representing the direction of flow in the segment $j$ of loop $i . \theta_{i, j}$ is considered to be +1 when fluid flows in clockwise direction and -1 if the direction is reversed. The frictional pressure drop in a segment $j$ of the loop $i$ can be calculated from

$$
\Delta P_{\mathrm{f}, i, j}=C_{\mathrm{f}, i, j} \frac{l_{i, j}}{D_{\mathrm{h}, i, j}} \frac{\rho_{i, j} V_{i, j}^{2}}{2}
$$

where $l_{i, j}$ and $D_{\mathrm{h}, i, j}$ are the segment (or control volume) length and hydraulic diameter, $\rho_{i, j}$ is the fluid average density, and $V_{i, j}$ is the average velocity in the segment $j$ of the loop $i$. The friction coefficient, $C_{\mathrm{f}, i, j}$, is a function of the Reynolds number defined based on the hydraulic diameter

$$
\operatorname{Re}_{i, j}=\frac{\rho_{i, j} V_{i, j} D_{\mathrm{h}, i, j}}{\mu_{i, j}} .
$$

The physical properties, $\rho$ and $\mu$ are calculated depending on whether single - or twophase flow prevails. For two-phase flow, Pehlivan, Hassan and Vaillancourt (2006) proposed the following correlations:

$$
\rho_{\mathrm{TP}}=\left(\frac{x}{\rho_{\mathrm{G}}}+\left(\frac{1-x}{\rho_{\mathrm{L}}}\right)\right)^{-1}, \quad \mu_{\mathrm{TP}}=\left(\frac{x}{\mu_{\mathrm{G}}}+\left(\frac{1-x}{\mu_{\mathrm{L}}}\right)\right)^{-1}
$$

where $x$ represents the quality and subscripts TP, G and L denote 'two-phase', 'gas' and 'liquid', respectively.

\section{Numerical procedure}

The flow network solution algorithm devised in this work is based on the modified Hardy Cross method recently reported (Karimi, Baschuk and $\mathrm{Li}, 2005$ ). The numerical solution begins with assigning a temporary flow direction to the flow network. The sum of the molar flow rates from all the inlets (with known compositions) is then divided uniformly among the gas flow channels. The molar flow rates and compositions in the downstream sections of the flow channels are calculated by subtracting the consumed reactants and adding the produced components. Water transport through the membrane due to the 
combined effects of electroosmotic drag and back diffusion is also considered. The conservation of mole equation is used to calculate the molar flow rates in the inlet and outlet manifolds based on the predefined directions and the assumed molar flow rates in the flow channels. To satisfy the conservation of energy equation, the pressure drop is calculated for each segment based on the local quality and appropriate pressure drop equations. The procedure is repeated until correct flow directions and molar flow rates are obtained for the whole flow network. The local concentration of the species is calculated accordingly.

\section{Results and discussion}

The input parameters for the fuel cell and stack flow model are classified as operating and design parameters. The design parameters are the fuel cell size, stack manifold and flow channel dimensions and configuration. Operating parameters include the stack current density, temperature, pressure, stoichiometry and the reactant composition at the stack inlet. Table 1 lists a summary of the operating and relevant design parameters used in the current study for the cathode side of PEM fuel cell stack.

The stack is considered to be composed of 31 cells, with two oxidant inlets at the end-points of the inlet manifold (\#1 and \#31) and one outlet at the middle of the exit manifold (\#16). This symmetric double-inlet-single-outlet configuration was shown to be the most effective scheme with minimal cell-to-cell voltage variations and parasitic losses (Karimi, Baschuk and Li, 2005). Fully humidified air at different pressures (depending upon the stack configuration) was considered to be injected into the stack.

Table 1 Parameters and properties used in the current Polymer Electrolyte Membrane fuel cell stack simulations

\begin{tabular}{lcc}
\hline Component & Parameter & Value \\
\hline Bipolar plate & $W$ & $0.15 \mathrm{~m}$ \\
& $H$ & $0.15 \mathrm{~m}$ \\
& $l$ & $1.8 \mathrm{~m}$ \\
& $d_{\mathrm{h}}$ & $1-2.2 \mathrm{~mm}$ \\
& $D_{\mathrm{h}}$ & $10 \mathrm{~mm}$ \\
& $N_{\mathrm{c}}$ & 3 \\
& $N_{\mathrm{t}}$ & 12 \\
Stack & $N_{\text {cells }}$ & 31 \\
& $N_{\text {inlets }}$ & $\mathbf{2}(\# 1, \# 31)$ \\
& $N_{\text {outlet }}$ & $1(\# 16)$ \\
& $T$ & $353 \mathrm{~K}$ \\
& $P_{\text {out }}^{\mathrm{a}}$ & $1 \mathrm{~atm}$ \\
& $J$ & $2,000-8,000 \mathrm{~A} \mathrm{~m}^{-2}$ \\
$\mathscr{S}_{\mathrm{c}}$ & 2.0 \\
$\lambda$ & 0.4 \\
\hline
\end{tabular}

${ }^{a}$ The inlet pressure varies depending on the flow network and operating design conditions. 
Figure $4 \mathrm{a}-\mathrm{d}$ display variations in different operating parameters in the cathode side of a fuel cell stack at the current density of $5,000 \mathrm{~A} \mathrm{~m}^{-2}$. Figure $4 \mathrm{a}$ shows the variation of $C_{\mathrm{O}_{2}}$ along the inlet and outlet manifolds and the gas flow channels. As expected, the $\mathrm{O}_{2}$ concentration is decreased uniformly along the flow channels as $\mathrm{O}_{2}$ is consumed and water produced due to the electrochemical reaction. The details of variations in $\mathrm{O}_{2}$ concentration along the three flow channels of the unit cell \#16 from the inlet to the outlet manifold is also shown in the accompanying figure. The $\mathrm{O}_{2}$ concentration remains constant throughout the outlet manifold.

Pressure distribution in the stack is illustrated in Figure $4 \mathrm{~b}$. There are two factors contributing in the pressure drop along the flow path in the stack. First, the total molar flow rate is increased along the flow channels because two moles of $\mathrm{H}_{2} \mathrm{O}$ produced for every mole of $\mathrm{O}_{2}$ consumed in the catalytic layer. As a result, water concentration is increased in the lower parts of the flow channels. This would increase the possibility of water vapour condensation which could initiate two-phase flow in the lower parts of the stack. This is evident from Figure $4 \mathrm{c}$ where the quality, $X$, decreased from 1 (singlephase) to 0.85 (two-phase) in the lower parts of the stack. Figure $4 \mathrm{~d}$ indicates that the Reynolds number varies along the flow path as the velocity, density and viscosity changes.

Figure 4 Spatial variations of operating parameters in the cathode side of a Polymer Electrolyte Membrane fuel cell stack $\left(J=5,000 \mathrm{~A} \mathrm{~m}^{-2}\right)$ (see online version for colours)

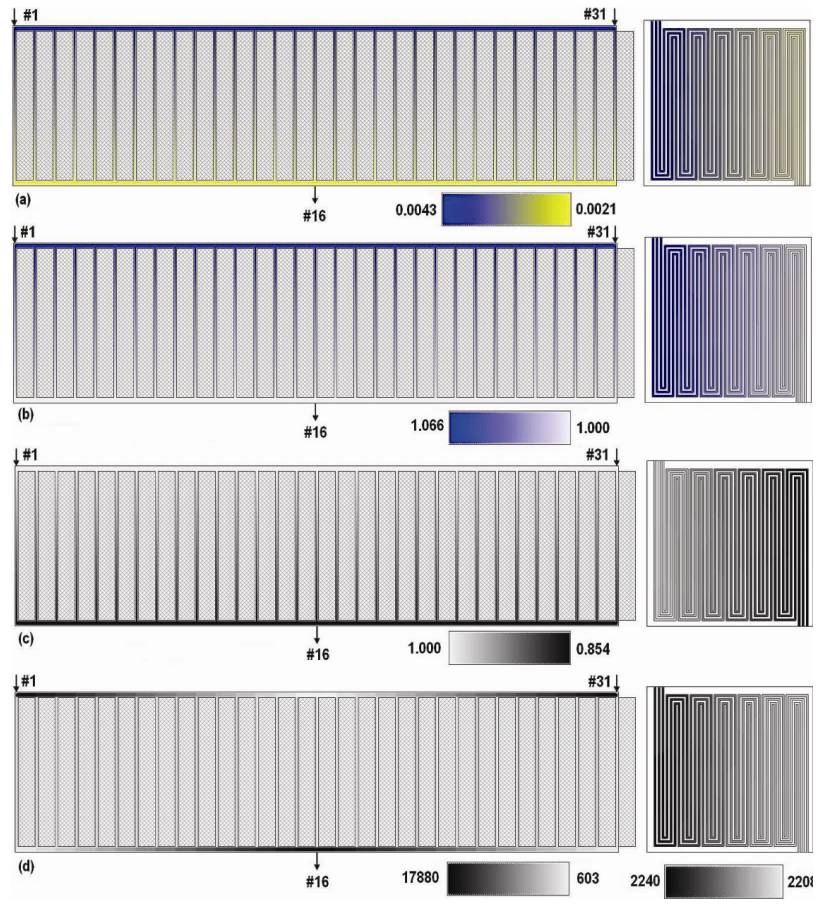

(a) $C_{\mathrm{O}_{2}}\left(\mathrm{~mol} \mathrm{l}^{-1}\right)$, (b) $P($ atm), (c) $X$ and (d) Re 
Figure 5 Variation of local operating conditions in the cathode side of a Polymer Electrolyte Membrane fuel cell $\left(J=5,000 \mathrm{~A} \mathrm{~m}^{-2}\right)$

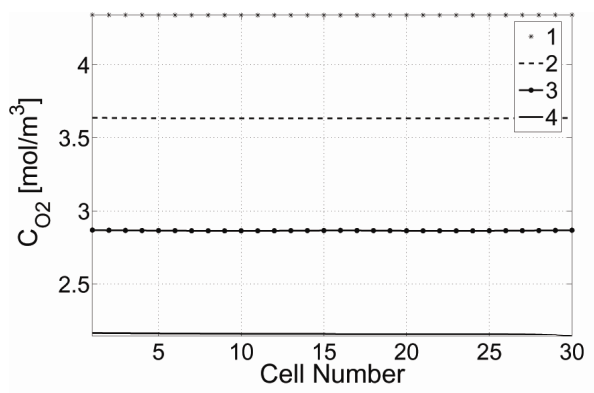

(a) $\mathrm{O}_{2}$ concentration

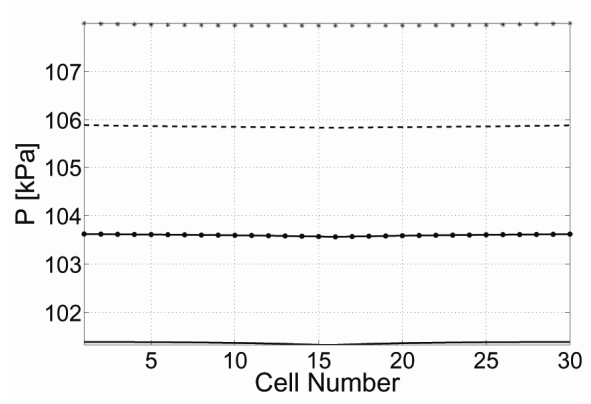

(c) Local Pressure

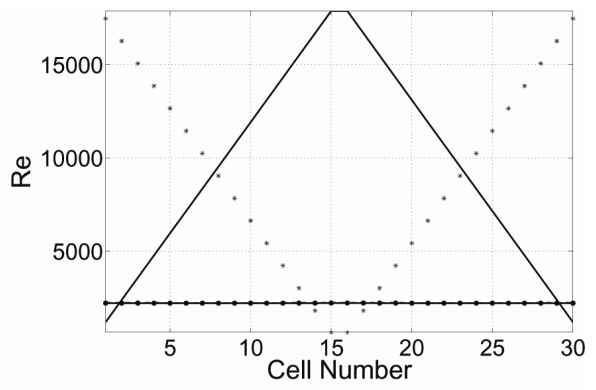

(b) Reynolds number

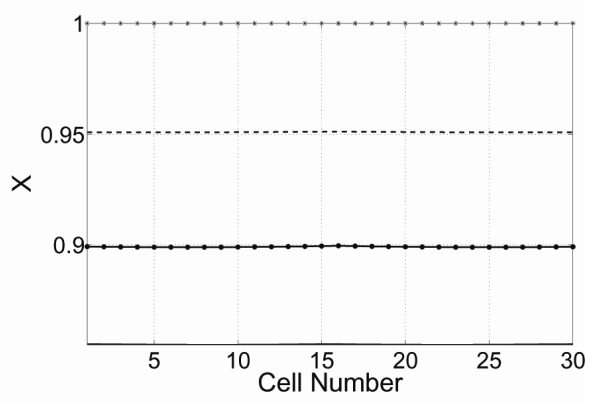

(d) Quality

Figure 6 Cross sections of various locations along the stack flow path (see online version for colours)

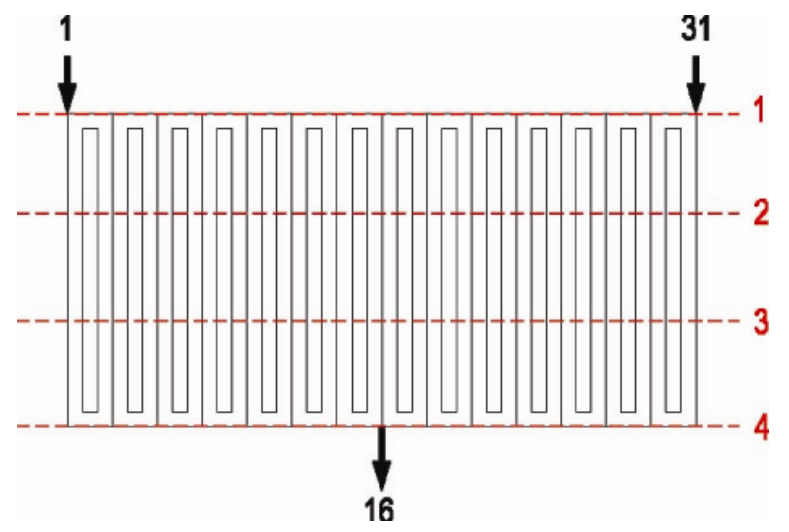

Figure 5 show the variation of various operating parameters in the cathode side of a PEM fuel cell stack. As indicated in Figure 6, four different locations are considered along the flow path; two along the inlet and outlet manifolds and two in the gas flow channels. Figure 5a displays the variations of the $\mathrm{O}_{2}$ concentration throughout the stack. As seen 
from this figure, although the $\mathrm{O}_{2}$ concentrations remain almost constant at different cross sections of the stack, it is decreased along the gas flow channels due to the oxygen reduction in the catalytic layer. Figure $5 \mathrm{~b}$ shows the variation of the Reynolds numbers in the manifolds and across the flow channels. The Reynolds number decreases along the inlet manifold from the endpoints towards the middle channels as the reactants are delivered to the flow channels. The flow division is almost uniform due to the large pressure drop in the flow channels compared with that of the inlet manifold. This results in a linear reduction in the Reynolds number. This phenomenon is repeated for the outlet manifold as the unreacted $\mathrm{O}_{2}$, nitrogen and water are collected and leave the stack. Variations in local pressures and qualities are shown in Figure $5 \mathrm{c}$ and d, respectively. The pressure decreases from the highest value at the inlet (manifold) to the outlet pressure (considered atmospheric in this work). The resulting quality distributions indicated in Figure $5 \mathrm{~d}$ reveals that two-phase flow could occur at the lower sections of the cathode. At a current density of $5,000 \mathrm{~A} \mathrm{~m}^{2}$, the minimum quality could reach a value of $85 \%$. It is worthwhile to note that such a quality is not appreciable to incept a major two-phase flow in the stack. This is due to very large liquid-to-gas density ratio; which leads to void fractions of $>99 \%$.

Figures 7 compare the pressure distributions and $\mathrm{O}_{2}$ concentrations calculated based on single- and two-phase flow correlations. It is seen that there is some differences between the two values however, the deviations are not appreciable. This is due to the very large void fraction values (close to 1 ) that prevail in the majority of the stack flow paths, as pointed out earlier.

Figure 7 Comparison of the calculated pressure distributions based on single-and two-phase flow correlations at different sections of the stack $\left(J=5,000 \mathrm{~A} \mathrm{~m}^{-2}\right)$

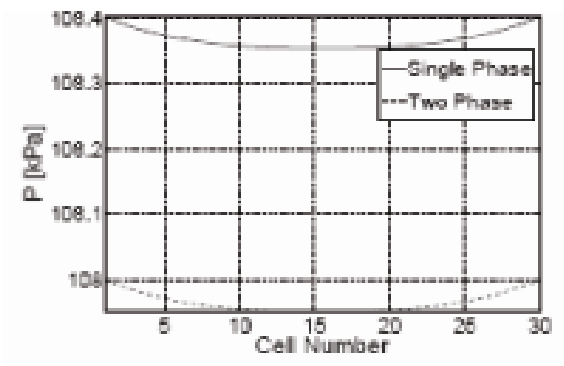

(a) Inlet manifold

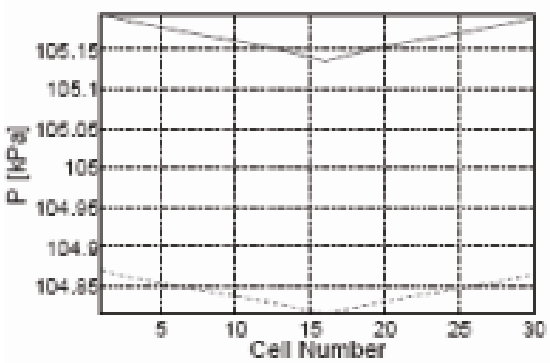

(c) Middle of the flow channels

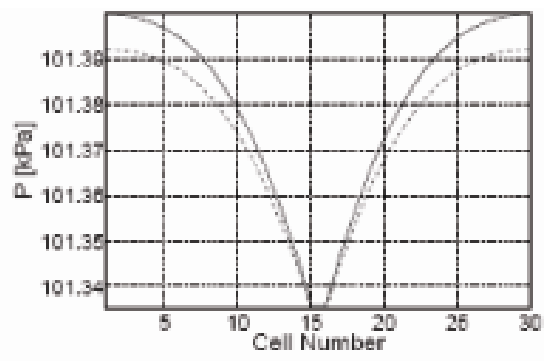

(b) Outlet manifold

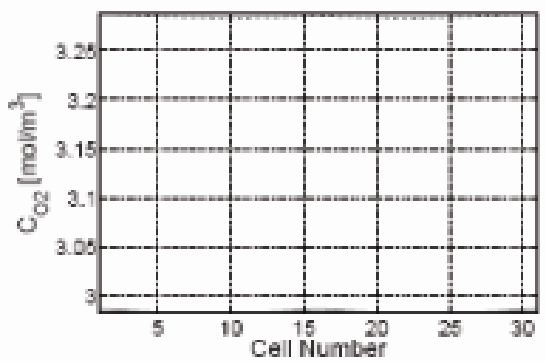

(d) Middle of the flow channels 
Figure 8 Variations of the minimum quality in the stack as functions of: (a) current density (b) flow channel hydraulic diameter

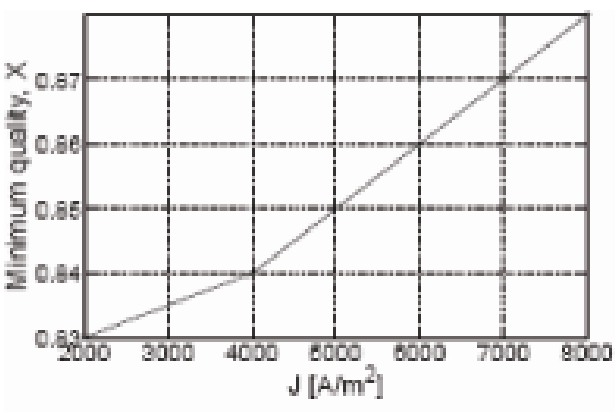

(a)

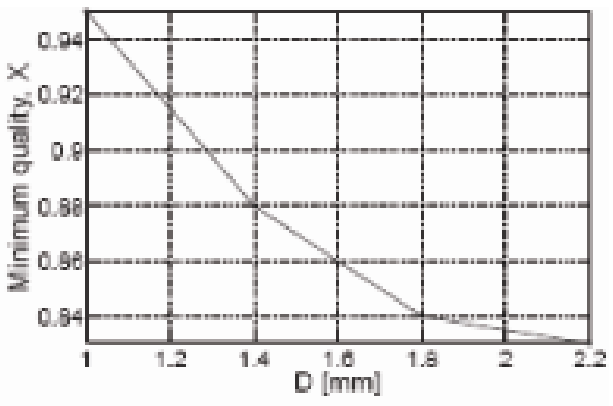

(b)

The effects of the current density, $J$, and the flow channel hydraulic diameter, $d_{\mathrm{h}}$, on the minimum quality are also investigated. Figure 8 a shows that as $J$ increases the minimum quality is also increases. There are two factors affecting the stack quality. As the current density increases, a larger $\mathrm{O}_{2}$ molar flow rate is required for the electrochemical reaction and a larger amount of water is produced. On the other hand, a larger inlet pressure is required to push the reacting $\mathrm{O}_{2}$ (accompanied with nitrogen from air and water vapour for humidification) through the stack. With higher stack inlet pressure, the incoming reactant mixture can be fully humidified with smaller amount of water content. The competition between the lower water content at the stack inlet and larger water production in the flow channels determines the flow qualities in the system. The current data indicated that the effect of the former is dominant. This is also evident from Figure $8 \mathrm{~b}$ where larger flow channel diameters reduces the stack inlet pressure, increases the inlet water content and decreases the quality in the system.

\section{Conclusions}

The Proton exchange membrane fuel cell is the most elegant of all fuel cell systems in terms of design and mode of operation and the first one put into practical applications. However, distributions in reactant species concentration in a PEM fuel cell due to local consumption of fuel and water transport through the membrane cause distributions in current density, temperature and water concentration in a PEM fuel cell and may shorten the life of the MEA. The possibility of the inception of two-phase flow in the cathode side of a PEM fuel cell stack and its impact on the stack performance has been investigated in this article. The distributions of pressure, molar flow rates, species concentrations and thermodynamic qualities were determined with a novel flow network model. The simulation results have revealed that under certain operating conditions the quality is lower than one for parts of the stack. However, the amount of the liquified water in the stack is not significant to cause a major pressure drop or an appreciable change in the $\mathrm{O}_{2}$ concentration. Effects of current density and channel diameter on the system quality are also investigated. 


\section{References}

Fell, S., Roth, J., Steidle, B., Baker, D., Gu, W., Mathias, M. and Schoeneweiss, M. (2002) 'Using CFD models to understand the impact of flow field design on PEM fuel cell performance', VDI Berichte, pp.579-600.

Greenway, S., Shimpalee, S., Lee, W-k. and Van Zee, J.W. (2002) 'The effect of flow-field configuration on PEMFC performance', Abstract \# 1135, 201 Meeting of The Electrochemical Society, May 12-17, Philadelphia, PA.

Karimi, G., Baschuk, J.J. and Li, X. (2005) 'Performance analysis and optimization of PEM fuel cell stacks using flow network approach', Journal of Power Sources, Vol. 147, pp.162-177.

Li, P.W., Chen, S.P. and Chyu, M.K. (2005) 'Novel gas distributors and optimization for high power density in fuel cells', Journal of Power Sources, Vol. 140, pp.311-318.

Pehlivan, K., Hassan, I. and Vaillancourt, M. (2006) 'Experimental study on two-phase flow and pressure drop in millimeter-size channels', Applied Thermal Engineering, Vol. 26, pp.1506-1514.

Shimpalee, S., Greenway, S., Spuckler, D. and Van Zee, J.W. (2004) 'Predicting water and current distributions in a commercial-size PEMFC', Journal of Power Sources, Vol. 135, pp.79-87.

Wang, C.Y. (2004) 'Fundamental models for fuel cell engineering', Chemical Reviews, Vol. 104, pp.4727-4766. 